\title{
Development of a Latent Heat Thermal Energy Storage Material-Based Refrigeration System
}

\author{
Taiwo O. Oni ${ }^{1 *}$, Jacob B. Awopetu ${ }^{1}$, Samson A. Adeleye ${ }^{1}$, Daniel C. Uguru-Okorie ${ }^{2}$, Anthony A. Adeyanju ${ }^{3}$, Niyi E. \\ Olukayode $^{1}$ \\ ${ }^{1}$ Department of Mechanical Engineering, Ekiti State University, Ado-Ekiti 360001, Nigeria \\ ${ }^{2}$ Department of Mechanical and Mechatronics Engineering, Federal University Oye-Ekiti, Oye-Ekiti 371106, Nigeria \\ ${ }^{3}$ Department of Mechanical and Manufacturing Engineering, University of West Indies, St. Augustine 00000, Trinidad and \\ Tobago
}

Corresponding Author Email: tooni1610@yahoo.com

https://doi.org/10.18280/ijht.390216

Received: 13 September 2020

Accepted: 20 March 2021

\section{Keywords:}

temperature, refrigeration, evaporator, performance, improvement, compressor work, refrigerating effect

\begin{abstract}
The present research focuses on application of thermal energy storage on a convectional refrigerator to enhance its performance. Salt hydrate was used as latent heat thermal energy storage (LHTES) material to convert the convectional refrigerator to a LHTES materialbased refrigerator. The cabinet of the convectional refrigerator was loaded with $10 \mathrm{~kg}$ of water at a temperature of $28^{\circ} \mathrm{C}$ and experiments were conducted on it to know the time taken for the evaporator temperature $\left(\mathrm{T}_{\mathrm{E}}\right)$ to reach $-5^{\circ} \mathrm{C}$, and determine the performance characteristics of the convectional refrigerator. The experiments were repeated on the LHTES material-based refrigerator to compare its performance characteristics with those of the convectional refrigerator. The results reveal that the evaporator of the LHTES material-based refrigerator attains the temperature of $-5^{\circ} \mathrm{C}$ forty minutes before the same temperature $\left(-5^{\circ} \mathrm{C}\right)$ was attained in the evaporator of the convectional refrigerator. For the interval of evaporator temperature $\left(-5^{\circ} \mathrm{C} \leq \mathrm{T}_{\mathrm{E}} \leq-1{ }^{\circ} \mathrm{C}\right)$ considered for evaluation of the performance characteristics of the refrigerators in this work, when $\mathrm{T}_{\mathrm{E}}$ drops from $1{ }^{\circ} \mathrm{C}$ to $5^{\circ} \mathrm{C}$, the coefficient of performance (COP) for the LHTES material-based refrigerator and convectional refrigerator decreases from 7.36 to 4.62 and 6.44 to 4.15 , respectively; the refrigerating effect decreases from $118.41 \mathrm{~kJ} / \mathrm{kg}$ to $111.80 \mathrm{~kJ} / \mathrm{kg}$ and $113.37 \mathrm{~kJ} / \mathrm{kg}$ to $106.69 \mathrm{~kJ} / \mathrm{kg}$, respectively; the compressor work increases from $15.10 \mathrm{~kJ} / \mathrm{kg}$ to $23.18 \mathrm{~kJ} / \mathrm{kg}$ and $17.60 \mathrm{~kJ} / \mathrm{kg}$ to $25.68 \mathrm{~kJ} / \mathrm{kg}$, respectively. The higher value of the COP and refrigerating effect, and the lower value of the compressor work of the LHTES material-based refrigerator compared with those of the convectional refrigerator imply that there is an improvement in the performance of the refrigerator with the LHTES material. The current work broadens research on the use of a LHTES materials to enhance the performance of a refrigerator
\end{abstract}

\section{INTRODUCTION}

One of the energy-consuming devices which are commonly used is a refrigerator. At present, not all countries in the world can satisfactorily meet energy demand of its citizens, and in some cases the cost of energy is high. One of the means of reducing energy consumption of refrigerators is to improve their performance. As a matter of fact, various attempts have been made to have an improvement in performance of refrigerators. These attempts, according to Makinde and Oni [1], include use of high-efficiency compressor substitution, increase in evaporator and condenser size with counterblow arrangement, increase in surface area and number of fins of evaporators, substitution of refrigerants with other ones, and use of composite insulation.

Another technique for performance improvement of refrigerators is utilization of latent heat thermal energy storage (LHTES) material [2], otherwise known as phase change material (PCM) [3, 4]. This will reduce the dependency on carbon-based fuels. Latent heat thermal energy storage (LHTES) materials are high latent heat content substances whose changes of state from solid (freezing) to liquid (melting), or vice versa, occur at almost constant temperature. During this process, huge amounts of energy are released or accumulated. This means that when LHTES materials attain their phase transition temperature, the absorption of heat by these materials continues without an appreciable rise in temperature until there is a total transformation to the liquid phase. Conversely, when the temperature of the LHTES material drops, the material previously in the liquid phase solidifies and the stored latent heat is released [2,4]. Latent heat storage (LHS) is classified under physical thermal energy storage, meaning that there is storage and retention of heat energy [5].

LHTES materials undergo only a slight change in volume and density through the process of phase change, their freezing/melting cycles are completely reversible, and they have chemical and physical stability over time. In addition, they have high volumetric latent heat storage capacity, high density, and high thermal conductivity [6].

Depending upon phase transformation, LHTES materials are classified into the following phase transformations: liquid- 
gas, solid-gas, solid-solid, and solid-liquid and vice versa. Majority of the LHTES materials considered for thermal energy storage are solid-liquid phase transition materials and are grouped based on the nature of the materials, such as organic, inorganic, and eutectics [4, 7]. Examples of organic LHTES materials are esters, paraffin waxes, alkanes, and alcohols fatty acids. The inorganic group includes metallic compounds metal alloys, salt hydrates, and salts. Those in the eutectic group could constitute a eutectic mixture with several materials which could be organic components, inorganic components, or a mixture of both (that is, organic-organic, inorganic-inorganic, or organic-inorganic) $[8,9]$.

LHTES materials have significant areas of applications such as in building [10], photovoltaic thermal [11], electric scooter battery system (lithium-ion batteries) [12], temperature management of greenhouses [13], high power electronic devices (such as micro-channel heat sinks) [14], and waste heat recovery systems [15].

Moreover, some researchers have considered the applications of phase change material (PCM), also known as LHTES material, in refrigerators. For example, Cheralathan et al. [16] experimentally investigated the performance of a refrigeration system incorporated with PCM. The experiment was based on cold thermal energy storage system. Their findings demonstrated the advantage of PCM thermal energy storage to the refrigerator

Wang et al. [17] tested a refrigeration system which incorporated LHTES material placed behind the compressor and condenser of the refrigerator. The results obtained from this experiment, showed that the refrigeration system's coefficient of performance improved between $6 \%$ and $8 \%$ as a result of the addition of the LHTES material.

A test conducted by Azzouz et al. [18] on domestic refrigerator with ice slab in contact with its evaporator showed that the refrigerator's energetic autonomy increased from just a few minutes in the refrigerator without LHTES materials to between 5 and 9 hours in the refrigerator with LHTES materials. The coefficient of performance of the system with the LHTES materials was increased between $5 \%$ and $15 \%$. This range of increase was dependent on the ambient temperature, the frequency of door openings, and the temperature at phase change of the LHTES materials.

By employing an aqueous ammonium chloride solution as PCM, a study was done by Gin et al. [19] to examine the effectiveness of PCM panel at maintaining a stable temperature inside the compartment of a freezer. The PCM panel was placed on the internal walls of the freezer. Decrease in energy consumption of the freezer during the defrost cycle and door openings was observed to be $8 \%$ and $7 \%$ respectively. For the freezer with PCM and the freezer without PCM, the rate of product temperature change during 4 hours of electrical power loss were $0.025^{\circ} \mathrm{C}$ per minute and $0.04^{\circ} \mathrm{C}$ per minute, respectively.

Cheng et al. [20] experimentally conducted an analysis on the performance of a fridge-freezer whose condenser pipes were fitted with PCM. The PCM used was prepared with paraffin and was used to store part of the condensation heat during the on-cycle and, thereafter, dissipated to the environment when the compressor was switched off. When compared with the conventional fridge-freezer, the fridgefreezer with PCM had a lower condensation temperature and $12 \%$ energy savings.

The performance of a refrigerator integrated with water gel as a phase change material was investigated by Alzuwaid et al.
[21]. The water gel was incorporated into the cabinet of the system. It was observed through the results that lower cabinet temperatures could be achieved through the use of the water gel as phase change material.

A mixture of water and vegetable oil was used by Rasta and Suamir [22] as a phase change material for application in a refrigeration system used to cool water. The inference from the investigation indicated that the phase change material decreased the freezing temperature of water inside the refrigeration system.

In order to analyse the variation of temperatures in the cabinet of a refrigerator, a phase change material was introduced by Maiorino et al. [23] within the cabinet of a refrigerator, attached to its bare tube evaporator placed below its racks. The refrigerator was equipped with tap water as phase change material, and the effect of different control settings on the performance of the system was investigated. It was submitted that the incorporation of the PCM reduced the fluctuations of the refrigerator's temperature during operation.

An attempt was made by Afzal et al. [24] by impregnating coconut oil, as a phase change material, underneath the rooftop and vacant spaces in door interior of a vehicle. Their results revealed that undesirable heating in the cabins and interior of the vehicle were prevented. In particular, the interior temperature of the vehicle's cabin was decreased by $13^{\circ} \mathrm{C}$.

Literatures reveal that the influences of LHTES materials on coefficient of performance and energy consumption of refrigeration systems have been extensively carried out. However, the effects of LHTES material on refrigerating effect and compressor work have not been considered in the previous works. Therefore, in the current research, other potentials of a LHTES material were explored by investigating the influence of salt hydrate (a LHTES material) on refrigerating effect, compressor work, evaporator temperature, and coefficient of performance of a refrigeration system. There are different types of hydrated salt, namely inorganic hydrates, organic hydrates, and gas hydrates. The salt hydrate used as the LHTES material in the present work is an inorganic hydrate. According to various reports [25-27], the salt hydrate has physical parameters. For example, it is in crystalline form, it is non-combustible and transparent. In addition, its water molecules are only loosely bonded to the compound, and the water molecules can be removed from the compound fairly easily through heating.

\section{RESEARCH METHODOLOGY}

\subsection{Selection of convectional refrigerator}

A single-door domestic refrigerator, which originally has no LHTES material, was used as the convectional refrigerator in the present research. The convectional refrigerator has the specifications shown in Table 1.

Table 1. Design specifications of the convectional refrigerator

\begin{tabular}{cc}
\hline Item & Specification \\
\hline Internal length of cabinet & $0.23 \mathrm{~m}$ \\
Internal breadth of cabinet & $0.23 \mathrm{~m}$ \\
Internal height of cabinet & $0.46 \mathrm{~m}$ \\
Internal diameter of the evaporator coil & $0.007 \mathrm{~m}$ \\
Internal diameter of the condenser coil & $0.003 \mathrm{~m}$ \\
Refrigerant & R-12
\end{tabular}




\subsection{Fabrication of LHTES material box}

The material used for the LHTES material box is aluminum sheet. The aluminum sheet was made into two boxes of different dimensions. The first box has length, breadth and height of $0.22 \mathrm{~m}, 0.22 \mathrm{~m}$ and $0.43 \mathrm{~m}$, respectively. The dimensions of the second box are length of $0.21 \mathrm{~m}$, breadth of $0.21 \mathrm{~m}$, and height of $0.42 \mathrm{~m}$. The second box was inserted centrally into the first one and the space between the two boxes was sealed with aluminum sheet metal. With that, a LHTES material box was formed. A vent, which serves as entrance of the LHTES material into the box, was made on top of the box. The box is shown in Figure 1.

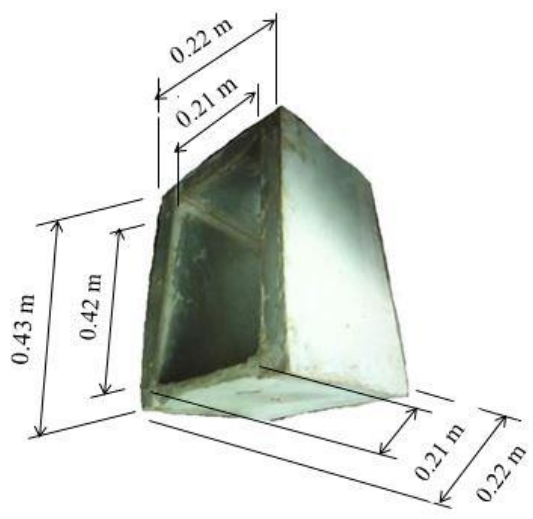

Figure 1. LHTES material box

\subsection{LHTES material and LHTES material-based refrigerator}

The LHTES material used in this work is salt hydrate, a crystalline salt molecule that is loosely attached to water molecules. The solution was prepared in the laboratory of Chemistry Department at Ekiti State University, Ado-Ekiti, Nigeria. To prepare the solution, $1 \mathrm{~kg}$ of dried salt (sodium chloride) was mixed with 9 liters (that is, $0.009 \mathrm{~m}^{3}$ ) of water. The density of water is $1000 \mathrm{~kg} / \mathrm{m}^{3}$ [28], hence the mass of the water is $9 \mathrm{~kg}$. This means that the ratio of water to sodium chloride is $9 \mathrm{~kg}: 1 \mathrm{~kg}$, which is 9:1. After the preparation of the LHTES material, it was poured into the box through a vent on its top.

The LHTES material box, which has already been filled with LHTES material, was used to cover the evaporator of the convectional refrigerator. This makes the convectional refrigerator to become a LHTES material-based refrigerator. The front view and back view of the LHTES material-based refrigerator are shown in Figure 2. The operation cycle of the LHTES material-based refrigerator is shown in Figure 3.

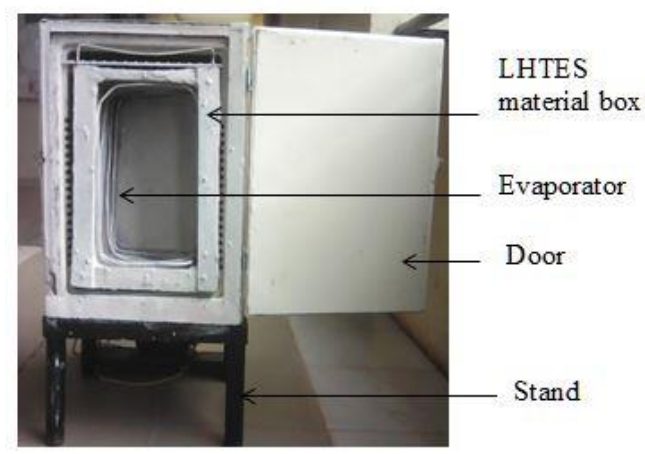

(a)

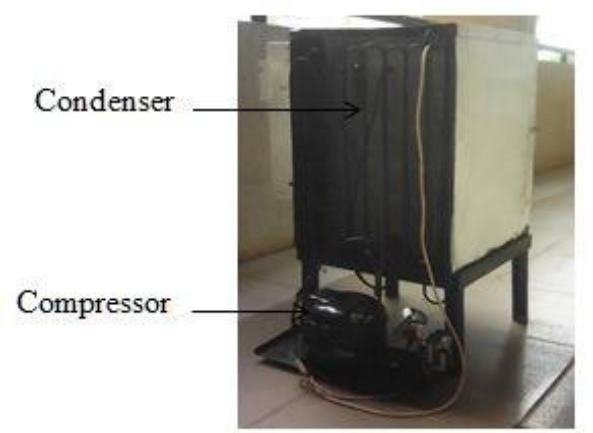

(b)

Figure 2. LHTES material-based refrigerator: (a) front view, (b) back view

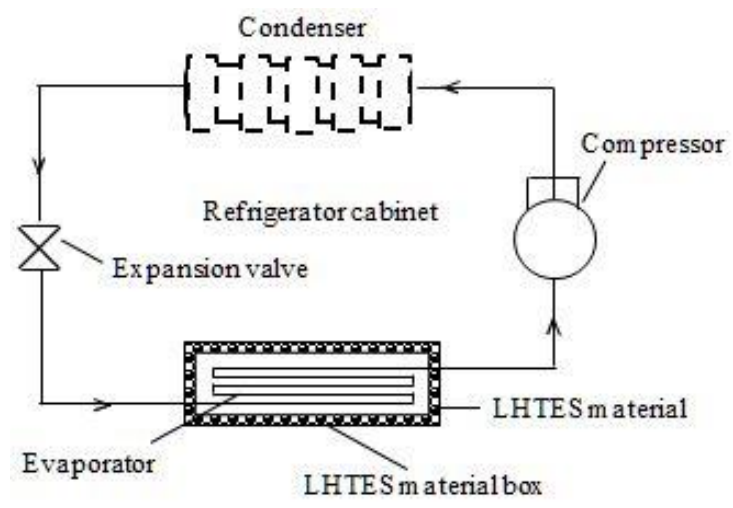

Figure 3. Cycle of operation of the LHTES material-based refrigerator

The refrigerant in the compressor compresses and leaves the compressor as vapor. The vapor refrigerant flows into the condenser, where it condenses into liquid, giving off its heat to the surrounding. The liquid refrigerant then flows to the expansion valve that restricts the flow of the refrigerant. From there, the refrigerant flows to the evaporator, where heat from the refrigerator cabinet is absorbed by the refrigerant and changes the refrigerant's state from liquid into vapor. Thus, cooling occurs. In addition, heat is released by the LHTES material to the liquid refrigerant, and the LHTES material stores latent heat for cooling.

\subsection{Experimental set-up and procedure}

The set-up of the experiment includes a convectional refrigerator, which is a single-door domestic refrigerator, with a cabinet that has internal dimensions of $0.23 \mathrm{~m} \times 0.23 \mathrm{~m} \times$ $0.46 \mathrm{~m}$ (see Table 1 above), LHTES material box, compressor, condenser and evaporator.

The experiments were conducted on the convectional refrigerator with its cabinet loaded with $10 \mathrm{~kg}$ of water at a temperature of $28^{\circ} \mathrm{C}$. Ambient temperature of $28^{\circ} \mathrm{C}$ was maintained and the evaporator was allowed to reach a temperature of $28^{\circ} \mathrm{C}$ before measuring the evaporator temperature by thermocouples. Readings were taken and recorded at intervals of 20 minutes until the temperature of the evaporator has reached $-5^{\circ} \mathrm{C}$.

After the end of the experiments with the convectional refrigerator, the water was off-loaded from it and its evaporator was cleaned. Then, the box filled with the LHTES material was used to cover the evaporator and by that means converted the convectional refrigerator to a LHTES material- 
based refrigerator. Experiments were conducted on the LHTES material-based refrigerator with a load of $10 \mathrm{~kg}$ of water at a temperature of $28^{\circ} \mathrm{C}$. Ambient temperature of $28^{\circ} \mathrm{C}$ was maintained and the evaporator was allowed to reach a temperature of $28^{\circ} \mathrm{C}$ before measuring its temperature at intervals of 20 minutes. Readings were taken and recorded until the temperature of the evaporator reached $-5^{\circ} \mathrm{C}$.

\section{COLLECTION OF DATA}

The data presented in this section were obtained during the experiments. The evaporator temperature $\left(\mathrm{T}_{\mathrm{E}}\right)$ at various time intervals for different load conditions of the refrigerators is given in Table 2.

The change of the evaporator temperature $\left(\Delta \mathrm{T}_{\mathrm{E}}\right)$ during time domain change $(\Delta t)$ is presented in Table 3 . The change of the evaporator temperature was obtained from Table 2 by subtracting evaporator temperature at a time interval $(\mathrm{t})$ from the evaporator temperature at its preceding time interval. Similarly, the time domain change $(\Delta t)$ was obtained from Table 2 by subtracting time interval $(\mathrm{t})$ from its preceding one. There are sixteen time domain changes in Table 3, and are named 20 (I), 20 (II), 20 (III) up to 20 (VI).

The refrigerators in the present research operate on actual or practical vapor compression refrigeration cycle whose temperature-entropy (T-s) diagram is shown in Figure 4. The state points 1, 2, 3, and 4 in the figure are the compressor inlet, compressor outlet, condenser outlet, and evaporator inlet, respectively. The evaporator temperature and condenser temperature are represented by $\mathrm{T}_{\mathrm{E}}$ and $\mathrm{T}_{\mathrm{c}}$, respectively.

The values of the enthalpy $(h)$ for the refrigerators at the various state points (that is, $h_{1}, h_{2}, h_{3}$, and $h_{4}$ ) were obtained from the table and P-h diagram of refrigerant R-12. The refrigerant R-12. does not reacts with the materials (such as evaporator, condenser, etc.) used in the refrigeration cycle. In addition, it has a low condensing pressure and a low condensing pressure $[3,28]$. The refrigerating effect $(\mathrm{R})$, compressor work (W), and COP of the refrigerators were calculated from the relations [29] given in Eqns. (1)-(3), respectively:

$$
\begin{gathered}
R=h_{1}-h_{4}=h_{1}-h_{3} \\
W=h_{2}-h_{1}
\end{gathered}
$$

Mathematically, the COP is written as:

$$
\begin{gathered}
C O P=\frac{\text { Refrigerating effect }}{\text { Compressor work }} \\
C O P=\frac{h_{1}-h_{4}}{h_{2}-h_{1}}=\frac{h_{1}-h_{3}}{h_{2}-h_{1}}
\end{gathered}
$$

The values of the refrigerating effect, compressor work, and COP are presented in Table 4 and Table 5.

\begin{tabular}{|c|c|c|c|c|c|c|c|c|c|c|c|c|c|c|c|c|c|c|}
\hline \multicolumn{2}{|c|}{ Time interval, $\mathrm{t}$ (min.) } & 0 & 20 & 40 & 60 & 80 & 100 & 120 & 140 & 160 & 180 & 200 & 220 & 240 & 260 & 280 & 300 & 320 \\
\hline \multirow{2}{*}{$\begin{array}{c}\text { Temp. of } \\
\text { evaporator, } \\
\text { TE }\left({ }^{\circ} \mathrm{C}\right)\end{array}$} & $\begin{array}{c}\text { Convectional } \\
\text { ref. }\end{array}$ & \multirow{2}{*}{$\begin{array}{l}28 \\
28\end{array}$} & 27 & 23 & 20 & 17 & 13 & 10 & 7 & 5 & 3 & 2 & 1 & 0 & -1 & -3 & \multirow[t]{2}{*}{-4} & \multirow[t]{2}{*}{-5} \\
\hline & $\begin{array}{c}\text { LHTES } \\
\text { material-based } \\
\text { ref. }\end{array}$ & & 26 & 22 & 18 & 15 & 10 & 7 & 4 & 3 & 1 & 0 & -1 & -2 & -4 & -5 & & \\
\hline
\end{tabular}

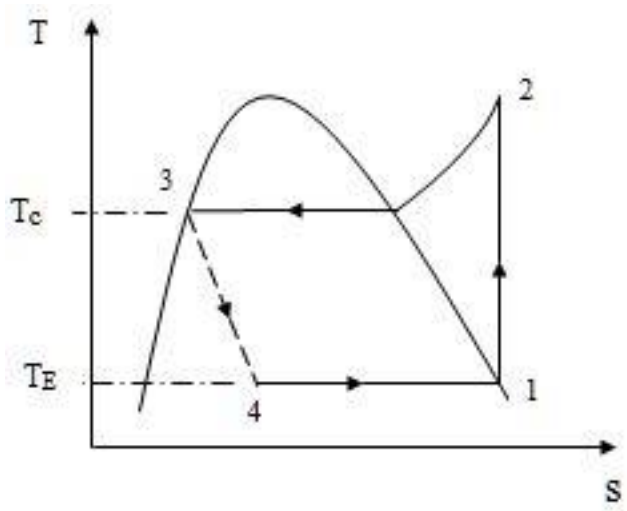

Figure 4. Temperature-entropy diagram of the refrigerators

\begin{tabular}{|c|c|c|c|c|c|c|c|c|c|c|c|c|c|c|c|c|c|}
\hline & $\Delta \mathrm{t}$ (min.) & $\begin{array}{l}20 \\
\text { (I) }\end{array}$ & $\begin{array}{l}20 \\
\text { (II) }\end{array}$ & $\begin{array}{c}20 \\
\text { (III) }\end{array}$ & $\begin{array}{c}20 \\
\text { (IV) }\end{array}$ & $\begin{array}{l}20 \\
(\mathrm{~V})\end{array}$ & $\begin{array}{c}20 \\
(\mathrm{VI}) \\
\end{array}$ & $\begin{array}{c}20 \\
\text { (VII) }\end{array}$ & $\begin{array}{c}20 \\
\text { (VIII) }\end{array}$ & $\begin{array}{c}20 \\
\text { (IX) }\end{array}$ & $\begin{array}{l}20 \\
(\mathrm{X}) \\
\end{array}$ & $\begin{array}{c}20 \\
(\mathrm{XI}) \\
\end{array}$ & $\begin{array}{c}20 \\
\text { (XII) }\end{array}$ & $\begin{array}{c}20 \\
\text { (XIII) }\end{array}$ & $\begin{array}{c}20 \\
\text { (XIV) }\end{array}$ & $\begin{array}{l}20 \\
(\mathrm{~V})\end{array}$ & $\begin{array}{c}20 \\
(\mathrm{VI}) \\
\end{array}$ \\
\hline \multirow[b]{2}{*}{$\begin{array}{l}\Delta \mathbf{T}_{\mathbf{E}} \\
\left({ }^{\circ} \mathrm{C}\right)\end{array}$} & $\begin{array}{c}\text { Convectional } \\
\text { ref. }\end{array}$ & -1 & -4 & -3 & -3 & -4 & -3 & -3 & -2 & -2 & -1 & -1 & -1 & -1 & -2 & \multirow[t]{2}{*}{-1} & \multirow[t]{2}{*}{-1} \\
\hline & $\begin{array}{c}\text { LHTES } \\
\text { material- } \\
\text { based ref. }\end{array}$ & -2 & -4 & -4 & -3 & -5 & -3 & -3 & -1 & -2 & -1 & 1 & -1 & -2 & -1 & & \\
\hline
\end{tabular}

Table 2. Evaporator temperature at various time intervals

Table 3. Change of evaporator temperature during time domain change

( $\Delta \mathrm{t}$ is the time domain change, $\Delta \mathrm{T}_{\mathrm{E}}$ is the change in temperature of evaporator)

Table 4. Refrigerating effect (R), compressor work (W), and COP of the convectional refrigerator

\begin{tabular}{cccccccc}
\hline $\mathbf{T}_{\mathbf{E}}\left({ }^{\circ} \mathbf{C}\right)$ & $\mathbf{T}_{\mathbf{c}}\left({ }^{\circ} \mathbf{C}\right)$ & $\boldsymbol{h}_{\boldsymbol{1}}(\mathbf{k J} / \mathbf{k g})$ & $\boldsymbol{h}_{\boldsymbol{2}}(\mathbf{k J} / \mathbf{k g})$ & $\boldsymbol{h}_{\mathbf{3}}=\boldsymbol{h}_{\boldsymbol{4}}(\mathbf{k J} / \mathbf{k g})$ & $\mathbf{R}(\mathbf{k J} / \mathbf{k g})$ & $\mathbf{W}(\mathbf{k J} / \mathbf{k g})$ & $\mathbf{C O P}$ \\
\hline 1 & 40 & 351.91 & 369.50 & 238.54 & 113.37 & 17.60 & 6.44 \\
0 & 40 & 351.48 & 370.00 & 238.54 & 112.94 & 18.52 & 6.10 \\
-2 & 42 & 350.62 & 372.00 & 240.57 & 110.05 & 21.38 & 5.15 \\
-4 & 43 & 349.76 & 374.00 & 241.60 & 108.16 & 24.25 & 4.46 \\
-5 & 44 & 349.32 & 375.00 & 242.63 & 106.69 & 25.68 & 4.15 \\
\hline
\end{tabular}


Table 5. Refrigerating effect (R), compressor work (W), and COP of the LHTES-based refrigerator

\begin{tabular}{cccccccc}
\hline $\mathbf{T}_{\mathbf{E}}\left({ }^{\circ} \mathbf{C}\right)$ & $\mathbf{T}_{\mathbf{c}}\left({ }^{\circ} \mathbf{C}\right)$ & $\boldsymbol{h}_{\boldsymbol{I}}(\mathbf{k J} / \mathbf{k g})$ & $\boldsymbol{h}_{\boldsymbol{2}}(\mathbf{k J} / \mathbf{k g})$ & $\boldsymbol{h}_{\mathbf{3}}=\boldsymbol{h}_{\boldsymbol{4}}(\mathbf{k J} / \mathbf{k g})$ & $\mathbf{R}(\mathbf{k J} / \mathbf{k g})$ & $\mathbf{W}(\mathbf{k J} / \mathbf{k g})$ & $\mathbf{C O P}$ \\
\hline 1 & 35 & 351.91 & 368.00 & 233.50 & 118.41 & 15.10 & 7.36 \\
0 & 35 & 351.48 & 369.00 & 233.50 & 117.98 & 17.52 & 6.73 \\
-2 & 38 & 350.62 & 370.00 & 236.51 & 114.11 & 19.38 & 5.89 \\
-4 & 39 & 349.76 & 372.00 & 237.52 & 112.23 & 22.25 & 5.05 \\
-5 & 39 & 349.32 & 373.50 & 237.52 & 111.80 & 23.18 & 4.62 \\
\hline
\end{tabular}

\section{RESULTS AND DISCUSSIONS}

\subsection{Evaporator temperature}

The variation in the evaporator temperature of the two refrigerators at the same time intervals is given in Table 2 above, and it is depicted in Figure 5. For the different observations of the experiments, it is evident from the figure that the evaporator temperature of the LHTES material-based refrigerator is lower than that of the convectional refrigerator. The reason adduced to it is as follows. When the compressor of the convectional refrigerator was running, heat was released by the cabinet to the refrigerant through free convection mode of heat transfer. But in the case of the LHTES material-based refrigerator, heat was released by the LHTES material to the refrigerant through conduction mode of heat transfer. The free convection heat transfer in the convectional refrigerator is slower than the conduction heat transfer in the LHTES material-based refrigerator. Therefore, for the same time intervals, the degree of reduction in the evaporator temperature of the convectional refrigerator is smaller than that of the LHTES material-based refrigerator. Consequently, the temperature of the evaporator of the LHTES material-based refrigerator is lower than that of the convectional refrigerator, for the same intervals of time. It can be seen in Figure 5 that the evaporator temperature of the LHTES material-based refrigerator and the convectional refrigerator reached a temperature of $-5^{\circ} \mathrm{C}$ at a period of 280 minutes and 320 minutes, respectively, after the start of the experiments. This means that the temperature of $-5^{\circ} \mathrm{C}$ was attained 40 minutes earlier in the LHTES material-based refrigerator.

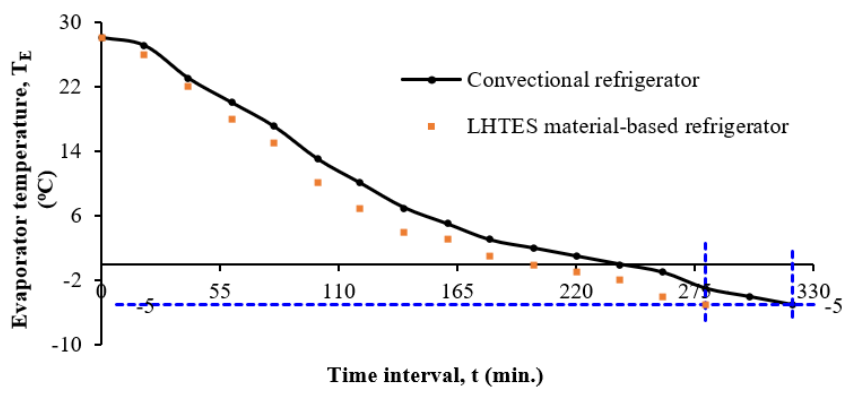

Figure 5. Evaporator temperature of the convectional refrigerator and LHTES material-based refrigerator at various time intervals

\subsection{Change of evaporator temperature during time domain change}

The change trend of the evaporator temperature during the time domain change is graphically demonstrated in Figure 6. During the first, second, third, and fourth time domain change of 20 minutes, denoted by 20 (I), 20 (II), 20 (III), and 20 (IV), respectively, in Table 3 above and Figure 6, the change of the evaporator temperature $\left(\Delta \mathrm{T}_{\mathrm{E}}\right)$ for the convectional refrigerator are $-1,-4,-3$, and $-3^{\circ} \mathrm{C}$, respectively. These translate to rate of change of evaporator temperature of $-0.05,-0.05,-0.05$, and, $0.05^{\circ} \mathrm{C} / \mathrm{min}$, respectively. For the LHTES material-based refrigerator, rate of change of evaporator temperature during the first, second, third, and fourth time domain change of 20 minutes are $-0.1,-0.2,-0.2$, and,$-0.15^{\circ} \mathrm{C} / \mathrm{min}$, respectively. The analysis further shows that during the eleventh up to the fourteenth time domain change of 20 minutes, represented by 20 (XI) up to the 20 (XIV), as appropriate, the change of the evaporator temperature $\left(\Delta \mathrm{T}_{\mathrm{E}}\right)$ is $-1,-1,-1$, and $-2^{\circ} \mathrm{C}$, appropriately, for the convectional refrigerator. These mean that the rate of change of evaporator temperature are -0.05 , $0.05,-0.05$, and, $-0.1^{\circ} \mathrm{C} / \mathrm{min}$, as appropriate. The corresponding rate of change of evaporator temperature for the LHTES material-based refrigerator (based on the values of its $\left.\Delta \mathrm{T}_{\mathrm{E}}\right)$ are $-0.05,-0.05,-0.1$, and,$-0.05^{\circ} \mathrm{C} / \mathrm{min}$, respectively. The change of the evaporator temperature for the convectional refrigerator during the fifteenth up to the sixteenth time domain change of 20 minutes are -0.05 , and, $-0.05^{\circ} \mathrm{C} / \mathrm{min}$, respectively. Overall, the results indicate that the LHTES material-based refrigerator perform better than the convectional refrigerator.

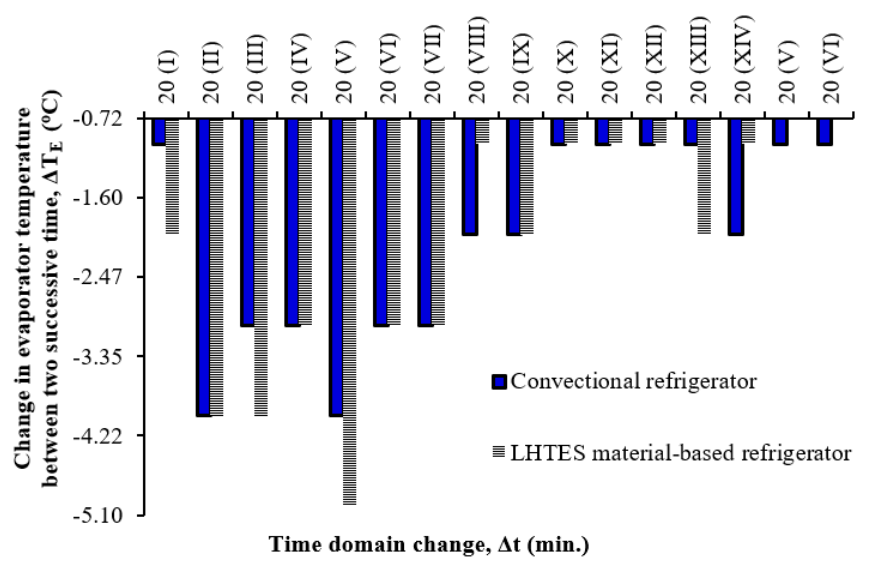

Figure 6. Change of evaporator temperature during time domain change of the convectional refrigerator and LHTES material-based refrigerator

\subsection{Coefficient of performance}

The coefficient of performance (COP) is a measure of the effectiveness of the refrigeration system [29]. The COP of the two refrigerators (presented in Table 4 and Table 5 above) is graphically displayed in Figure 7 . For the interval of evaporator temperature $\left(-5^{\circ} \mathrm{C} \leq \mathrm{T}_{\mathrm{E}} \leq-1{ }^{\circ} \mathrm{C}\right)$ considered for evaluation of performance characteristics in this work, when $\mathrm{T}_{\mathrm{E}}$ decreased from $1^{\circ} \mathrm{C}$ to $-5^{\circ} \mathrm{C}$, the COP of the LHTES material-based refrigerator and convectional refrigerator decreases from 7.36 to 4.62 and 6.44 to 4.15 , respectively. It is therefore evident from the figure that the COP of the LHTES 
material-based refrigerator is higher than that of the convectional refrigerator, meaning that the performance of the former is better than of the latter.

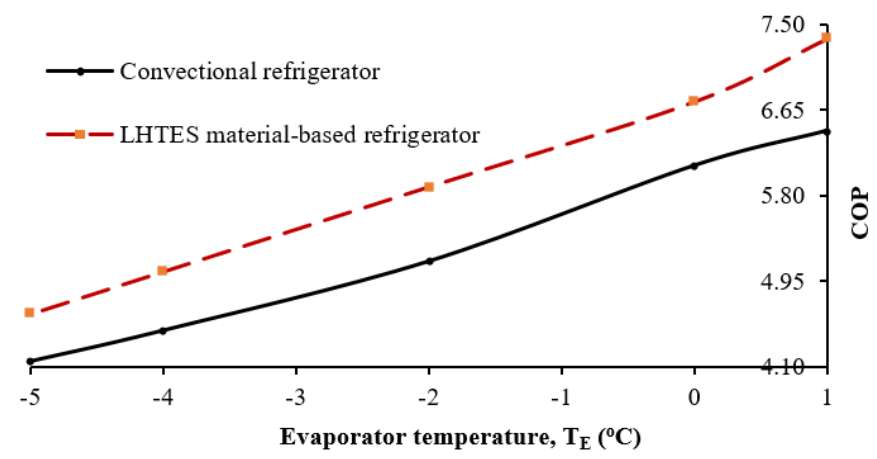

Figure 7. COP of the convectional refrigerator and LHTES material-based refrigerator

\subsection{Refrigerating effect}

The quantity of heat absorbed by the refrigerant from the cabinet of the refrigerator is referred to as its refrigerating effect [29]. Figure 8 shows that for the interval of evaporator temperature $\left(-5^{\circ} \mathrm{C} \leq \mathrm{T}_{\mathrm{E}} \leq-1{ }^{\circ} \mathrm{C}\right)$ considered for evaluation of refrigerating effect, when the evaporator temperature decreased from $1^{\circ} \mathrm{C}$ to $-5^{\circ} \mathrm{C}$, the refrigerating effect of the convectional refrigerator diminishes from $113.37 \mathrm{~kJ} / \mathrm{kg}$ to $106.69 \mathrm{~kJ} / \mathrm{kg}$. For the refrigerator with LHTES material, the refrigerating effect diminishes from $118.41 \mathrm{~kJ} / \mathrm{kg}$ and 111.80 $\mathrm{kJ} / \mathrm{kg}$. This clearly indicates that the refrigerating effect of the LHTES material-based refrigerator is higher than that of the conventional refrigerator. The higher value of the refrigerating effect of the LHTES material-based refrigerator confirms its better performance over the convectional refrigerator.

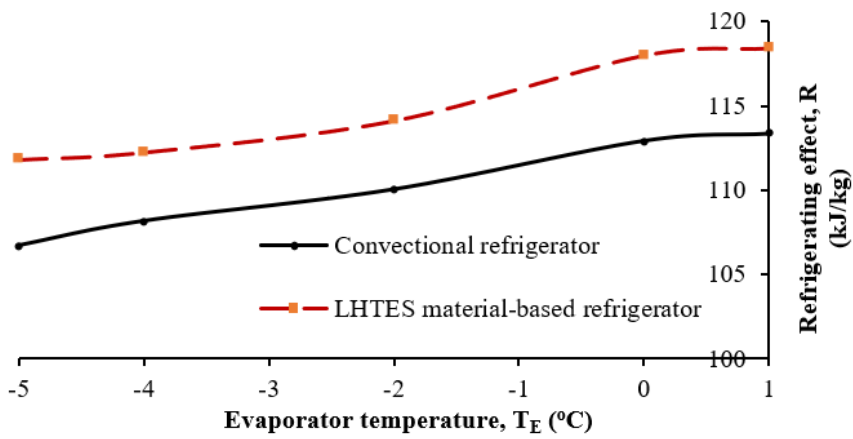

Figure 8. Refrigerating effect of the convectional refrigerator and LHTES material-based refrigerator

\subsection{Compressor work}

The effect which the LHTES material has on the compressor work of the refrigerators is depicted in Figure 9. As indicated therein, the compressor work of the LHTES material-based refrigerator is less than that of the convectional refrigerator. The compressor work increases from $17.60 \mathrm{~kJ} / \mathrm{kg}$ to 25.68 $\mathrm{kJ} / \mathrm{kg}$ for the convectional refrigerator as the evaporator temperature dropped from $1{ }^{\circ} \mathrm{C}$ to $-5^{\circ} \mathrm{C}$, whereas it increases from $15.10 \mathrm{~kJ} / \mathrm{kg}$ to $23.18 \mathrm{~kJ} / \mathrm{kg}$ for the LHTES material-based refrigerator. The reduction in the compressor work of the LHTES material-based refrigerator establishes its performance improvement compared with the convectional refrigerator.

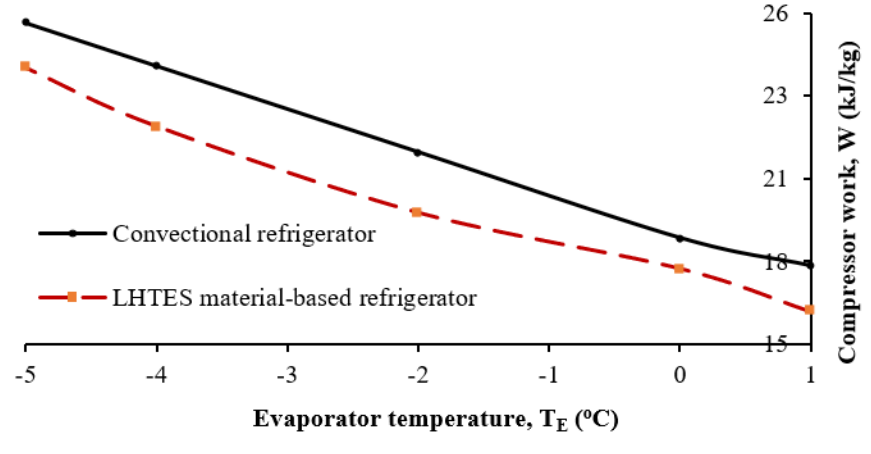

Figure 9. Compressor work of the convectional refrigerator and LHTES material-based refrigerator

\section{CONCLUSIONS}

The performance characteristics of two different refrigerators, namely a convectional refrigerator and an LHTES material-based refrigerator, were investigated. The cabinet of the refrigerators was loaded with $10 \mathrm{~kg}$ of water at a temperature of $28^{\circ} \mathrm{C}$, and experiments were conducted, in succession, on the refrigerators to ascertain the effects of the LHTES material on the performance of the refrigeration system.

The results clearly reveal that the temperature of the evaporator of the LHTES material-based refrigerator is lower than that of the convectional refrigerator, for the same intervals of time. In addition, there is an increase in the COP and refrigerating effect, and a decrease in the compressor work of the LHTES material-based refrigerator compared with those of the convectional refrigerator. These findings would, no doubt, inform researchers of other potentials of a LHTES material in improving on performance of a refrigerator. Therefore, the current work can be reliably applied to related problems in refrigeration.

\section{ACKNOWLEDGMENT}

The authors appreciate the assistance provided by Chemistry Department at Ekiti State University, Ado-Ekiti, Nigeria to prepare the LHTES material in its laboratory.

\section{REFERENCES}

[1] Makinde, M.T., Oni, T.O. (2019). Improvement on energy consumption of household refrigerator. Current Journal of Applied Science and Technology, 36(2): 1-15. https://doi.org/10.9734/CJAST/2019/v36i230225

[2] Zalba, B., Marı'n, J.M., Cabeza, L.F., Mehling, H. (2003). Review on thermal energy storage with phase change: materials, heat transfer analysis and applications. Applied Thermal Engineering, 23(3): 251-283. https://doi.org/10.1016/S1359-4311(02)00192-8

[3] Begeal, C., Decker, T. (2011). Solar thermal energy storage. In: Barnes, F.S. and Levine, J.G., (eds) Large Energy Storage Systems Handbook. CRC Press, Boca Raton.

[4] Nazir, H., Batool, M., Osorio, F.J.B., Isaza-Ruiz, M., Xu, X., Vignarooban, K., Phelan, P., Inamuddin, A., Kannan, A.M. (2019). Recent developments in phase change 
materials for energy storage applications: A review. International Journal of Heat and Mass Transfer, 129: 491-523.

https://doi.org/10.1016/j.ijheatmasstransfer.2018.09.126

[5] Mohamed, S.A., Al-Sulaiman, F.A., Ibrahim, N.I., Zahir, M.H., Al-Ahmed, A., Saidur, R. (2017). A review on current status and challenges of inorganic phase change materials for thermal energy storage systems. Renewable and Sustainable Energy Reviews, 70: 1072-1089. https://doi.org/10.1016/j.rser.2016.12.012

[6] Kulacki, F.A. (2015). Thermal Energy Storage using Phase Change Materials - Fundamentals and Applications. Springer, New York.

[7] Pielichowska, K., Pielichowski, K. (2014). Phase change materials for thermal energy storage. Progress in Materials Science, 65: 67-123. https://doi.org/10.1016/j.pmatsci.2014.03.005

[8] Kenisarin, M.M. (2010). High-temperature phase change materials for thermal energy storage. Renewable and Sustainable Energy Reviews, 14(3): 955-970. https://doi.org/10.1016/j.rser.2009.11.011

[9] Nazir, H., Batool, M., Ali, M., Kannan, A.M. (2018). Fatty acids based eutectic phase change system for thermal energy storage applications. Applied Thermal Engineering, 142: 466-475. https://doi.org/10.1016/j.applthermaleng.2018.07.025

[10] Cabeza, L.F., Castell, A., Barreneche, C., de Gracia, A., Ferna'ndez, A.I. (2011). Materials used as PCM in thermal energy storage in buildings: A review. Renewable and Sustainable Energy Reviews, 15(3): 1675-1695. https://doi.org/10.1016/j.rser.2010.11.018

[11] Hachem, F., Abdulhay, B., Ramadan, M., El-Hage, H., El-Rab, M.G., Khaled, M. (2017). Improving the performance of photovoltaic cells using pure and combined phase change materials - experiments and transient energy balance. Renewable Energy, 107: 567575. https://doi.org/10.1016/j.renene.2017.02.032

[12] Khateeb, S.A., Farid, M.M., Selman, J.R., Al-Hallaj, S. (2004). Design and simulation of lithium-ion battery with phase change material thermal management system for an electric scooter. Journal of Power Sources, 128(2): 292-307.

https://doi.org/10.1016/j.jpowsour.2003.09.070

[13] Llorach-Massana, P., Peña, J.R., Montero, J.I. (2017). Analysis of the technical, environmental and economic potential of phase change materials (PCM) for root zone heating in Mediterranean greenhouses. Renewable Energy, 103: 570-581. https://doi.org/10.1016/j.renene.2016.11.040

[14] Waterson, M. (2017). The characteristics of electricity storage, renewables and markets. Energy Policy, 104: 466-473. https://doi.org/10.1016/j.enpol.2017.01.025

[15] Nardin, G., Meneghetti, A., Magro, F.D., Benedetti, N. (2014). PCM-based energy recovery from electric arc furnaces. Applied Energy, 136: 947-955. https://doi.org/10.1016/j.apenergy.2014.07.052

[16] Cheralathan, M., Velraj, R., Renganarayanan, S. (2007). Performance analysis on industrial refrigeration system integrated with encapsulated PCM-base cool thermal energy storage system. International Journal of Energy Research, 31(14):

1398-1413. https://doi.org/10.1002/er.1313

[17] Wang, F., Maidment, G., Missenden, J., Tozer, R. (2007). The novel use of phase change materials in refrigeration plant. Part 1: Experimental investigation. Applied Thermal Engineering, 27(17-18): 2893-2901. https://doi.org/10.1016/j.applthermaleng.2005.06.011

[18] Azzouz, K., Leducq, D., Gobin, D. (2009). Enhancing the performance of household refrigerators with latent heat storage: An experimental investigation. International Journal of Refrigeration, 32(7): 1634-1644. https://doi.org/10.1016/j.ijrefrig.2009.03.012

[19] Gin, B., Farid, M.M., BansaL, P.K. (2010). Effect of door opening and defrost cycle on a freezer with phase change panels. Energy Conversion and Management, 51(12): 2698-2706. https://doi.org/10.1016/j.enconman.2010.06.005

[20] Cheng, W.L., Mei, B.J., Liu, Y.N., Huang, Y.H., Yuan, X.D. (2011). A novel household refrigerator with shapestabilized PCM (Phase Change Material) heat storage condensers: An experimental investigation. Energy, 36(10): 5797-5804. https://doi.org/10.1016/j.energy.2011.08.050

[21] Alzuwaid, F., Ge, Y.T., Tassou, S.A., Raeisi, A., Gowreesunker, L. (2015). The novel use of phase change materials in a refrigerated display cabinet: An experimental investigation. Applied Thermal Engineering, 75: 770-778. https://doi.org/10.1016/j.applthermaleng.2014.10.028

[22] Rasta, I.M., Suamir, I.N. (2018). The role of vegetable oil in water based phase change materials for medium temperature refrigeration. Journal of Energy Storage, 15: 368-378. https://doi.org/10.1016/j.est.2017.12.014

[23] Maiorino, A., Duca, M.G.D., Mota-Babiloni, A., Greco, A., Aprea, C. (2019). The thermal performances of a refrigerator incorporating a phase change material. International Journal of Refrigeration, 100: 255-264. https://doi.org/10.1016/j.ijrefrig.2019.02.005

[24] Afzal, A., Saleel, C.A., Badruddin, I.A., Khan, T.M.Y., Kamangar, S., Mallick, Z., Samuel, O.D., Soudagar, M.E.M. (2020). Human thermal comfort in passenger vehicles using an organic phase change material - an experimental investigation, neural network modelling, and optimization. Building and Environment, 180: 1-14. https://doi.org/10.1016/j.buildenv.2020.107012

[25] What are Hydrates? https://blog.prepscholar.com/whatare-hydrates-definition-naming-and-examples, accessed on Feb. 21, 2021.

[26] Sodium Chloride: Properties. https://www.infoplease.com/encyclopedia/science/chem istry/elements/sodium-chloride/properties, accessed on Feb. 21, 2021.

[27] Types of Hydrated Salt. https://www.google.com/search?ei=OIMyYKWgN6mD jLsPyK-

pqAs\&q=types+of + hydrated + salt \&oq=types + of + hydrat ed+salt\&gs_lcp=Cgdnd3Mtd216EAwyBwgAEEcQsAM yBwgAEEcQsAMyBwgAEEcQsAMyBwgAEEcQsAM yBwgAEEcQsAMyBwgAEEcQsAMyBwgAEEcQsAM yBwgAEEcQsANQAFgAYNpbaAZwAngAgAH1AYg B9QGSAQMyLTGYAQCqAQdnd3Mtd216yAEIwAEB $\&$ sclient $=$ gwswiz\&ved=0ahUKEwilnKyWrPvuAhWpAWMBHchXC rUQ4dUDCA0, accessed on Feb. 21, 2021.

[28] Baehr, H.D., Stephan, K. (2006). Heat and Mass Transfer. Springer, Berlin, 627.

[29] Andrew, D.A., Carl, H.T., Alfred, F.B. (2004). Modern Refrigeration and Air Conditioning. The Goodheart- 
Willcox Company Inc., Illinois, 664.

\section{NOMENCLATURE}

$\begin{array}{ll}\mathrm{h} & \text { enthalpy, } \mathrm{kJ} / \mathrm{kg} \\ \mathrm{R} & \text { refrigerating effect, } \mathrm{kJ} / \mathrm{kg} \\ \mathrm{T} & \text { Temperature, }{ }^{\circ} \mathrm{C} \\ \mathrm{t} & \text { time interval, min. } \\ \mathrm{W} & \text { compressor work, } \mathrm{kJ} / \mathrm{kg} \\ \Delta \mathrm{t} & \text { time domain change, } \mathrm{min} .\end{array}$

change of temperature, ${ }^{\circ} \mathrm{C}$

\section{Subscripts}

1

compressor inlet, evaporator outlet compressor outlet, condenser inlet condenser outlet, expansion valve inlet expansion valve outlet, evaporator inlet evaporator condenser 